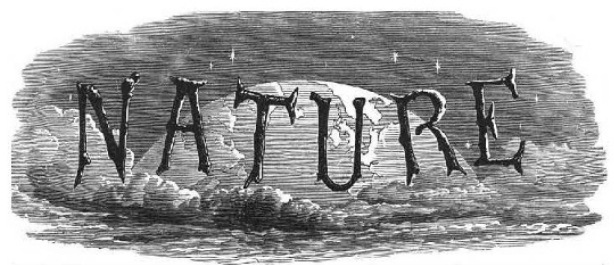

SATURDAY, FEBRUARY I4, I93I.

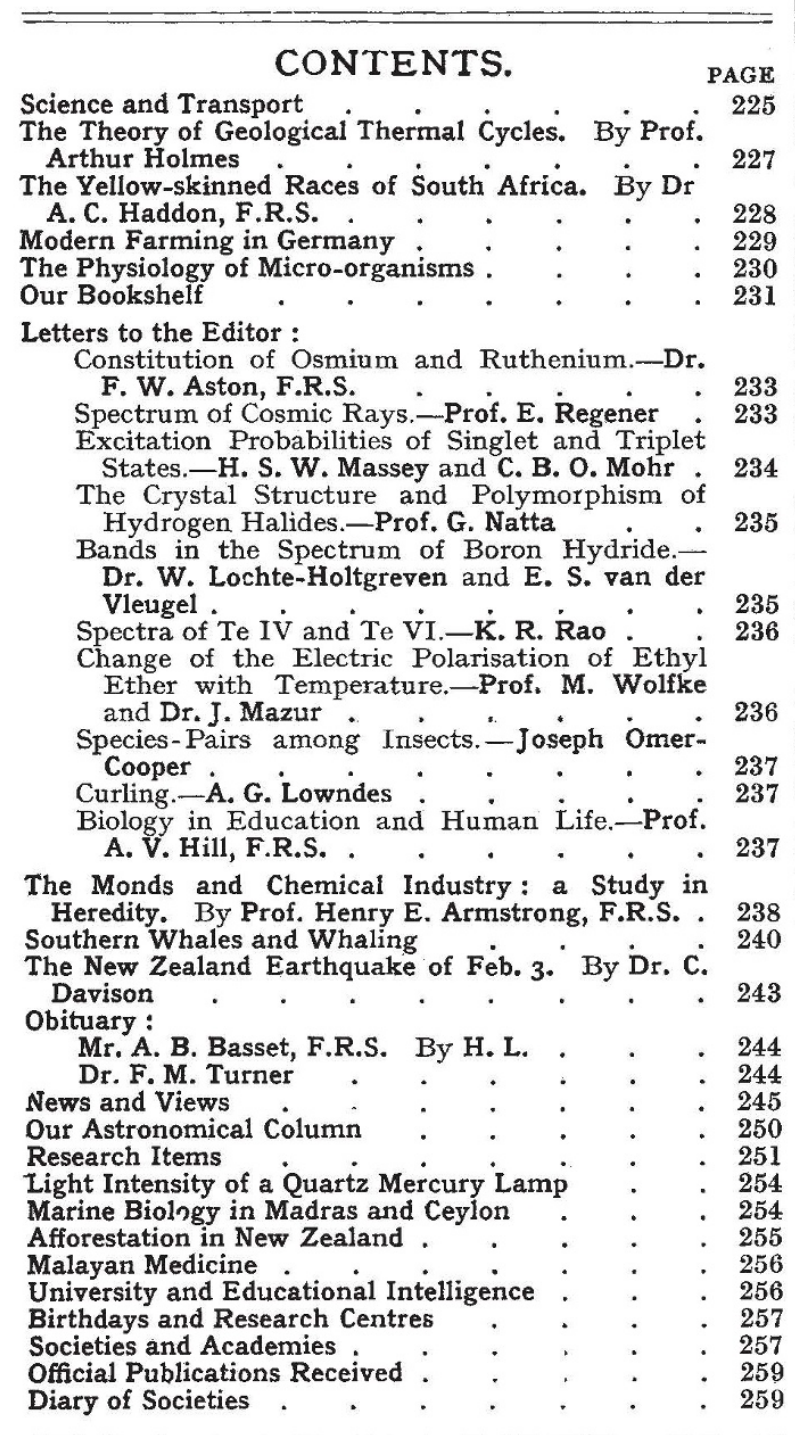

Edtitorial and Publishing Offices:

MACMILLAN \& CO., LTD.,

ST. MARTIN'S STREET LONDON, W.C.2.

Editorial communications should be addressed to the Editor.

Advertisements and business letters to the Publishers.

Telephone Number: GERRARD 8830.

Telegraphic Address: PHUSIS, WESTRAND, LONDON

\section{Science and Transport.}

T $\mathrm{N}$ few if in any departments of civil or industrial life has applied science introuluced more revolutionary changes in the last hundred years than in that of transport. It would be difficult, however, to find any other aspect of civil life which has been allowed to develop along more haphazard lines or in which the utilisation of the results of scientific discoveries has been more divorced from scientific organisation and control. One and a half million people, or nearly eight per cent of the employed population of Britain, are directly engaged in one or other of the branches of transport. Regarded solely as an industry, it is, therefore, of the utmost importance that efficient management and wise administration should maintain the highest possible standard of efficiency and economic development of the transport industry. From the wider view of transport as an integral and indispensable part of the national structure, it is impossible to exaggerate the importance of adequate, efficient, and cheap transport facilities, particularly in a country such as Great Britain, in which trade consists so largely in the importation of food and raw materials and the exportation of manufactured goods.

The Royal Commission on Transport alludes in its recently published final report* to the casual and haphazard way in which earlier forms of transport, particularly road transport, have been allowed to develop, and while regarding air transport as outside the scope of its inquiry, expresses the hope that timely guidance will ensure the development of this infant form of transport along sound lines. Many of the main difficulties in the present situation are indeed, as in the case of London, the result of lack of vision on the part of everyone concerned. The continued unchecked or uncontrolled development of road transport in competition with rail transport will undoubtedly have very serious evil results, and, apart from affecting the financial stability of those who provided transport facilities, will also hamper the economic progress of the nation.

The case of the railways provides a classic example of the burden which ignorance and prejudice can place on posterity; and the extremely high prices which in the nineteenth century our railways were compelled to pay for land to buy off influential opposition are an important factor in their presentday difficulties, and one from which other countries are relatively free. It is to be hoped that the lesson has been sufficiently well learnt to ensure general support for the Commissioners' recommendations

* London: H.M. Stationery Office. Cmd. 3751.

No. 3198, VoL. 127] 
regarding compensation in the case of privately owned bridges carrying public highways.

The report by no means holds the railways free from responsibility for some of their present difficulties. To some extent the 'grouping' under the Railway Act of 1921 is unscientific and not sufficiently geographical. To scientific minds the criticism in regard to the speed of railway journeys, particularly long-distance runs, will appear not a little scathing, and the railways are reminded that facilities create traffic.

On the broad issues as between road and rail transport, the report stresses the advantage of rail transport in the case of long distances and heavy loads, and few of the recommendations can be more unquestionable than that which asserts that it is not in the national interest to encourage the diversion of heavy goods traffic from the railways to the roads. Such diversions add greatly to the expenditure on highways, and tend to make the railways unremunerative without conferring any commensurate advantage. As regards long-distance travel, the ranways have not made full use of their immense advantage of speed, and there is little doubt that with a little more attention to the amenities of railway travel on the lines recommended, medium- and long-distance passenger road transport would largely disappear as a result of diminished demand.

The report considers that much of the competition between road and railway and other rorms of transport is due to the fact that the wages and general conditions of service in the road haulage industry leave much to be desired, and Sir W. G. Lobjoit's reservation on the recommendation for licensing of road hauliers was due not to any doubt as to the unsatisfactory conditions of wages and of labour, but to doubts as to the possibility of imposing conditions upon small firms and owner drivers. The labour aspect of road transport is, indeed, of fundamental importance, not only from the economic aspect in securing fair and satisfactory conditions of wages and hours of work, as well as in eliminating unfair competition and diversion of traffic into channels not to the public advantage, but also from the safety point of view. Insufficient attention has been given to the health and general physical fitness of transport drivers. In particular, the establishment of hostels or rest-houses for longdistance drivers, who form one of the occupational classes most highly infected with venereal disease, is a provision much needed if the efficiency of the driver is to be maintained and this serious factor in the causation of road accidents eliminated.
On the policy adopted by the railways of meeting road competition by themselves developing road transport, the Commission, while welcoming it so far as better co-ordination of rail and road transport is secured, makes the trenchant comment that the large capital sums expended in establishing such services would be better applied to the electrification of suburban lines. It is to such electrification, the improvement of omnibus services, and possibly to tube railways, that the Commissioners obviously look for the handling of the passenger traffic in large cities like London, Glasgow, Liverpool, Manchester, etc., at certain 'rush' hours, in place of the tramway systems, which they condemn as obsolete.

An important feature in transport development to which the report directs attention is that of research on road problems and the ceaseless endeavour to ensure that the highway is adequate not only for the traffic it has to bear at the present time, but also for that which it is likely to carry in the future. Much valuable research is being carried out by the Ministry of Transport, with the collaboration of the National Physical Laboratory, on such matters as the effects of varying certain factors in the design and construction of concrete roads, the conditions which give rise to the skidding of vehicles, and the effect of variations in the wheel diameters in the damage caused to roads. To enable experiments to be carried out under practical conditions without interference from general traffic, and to enable particular road surfaces to be studied under known traffic conditions, a special experimental road has been constructed near an experimental station.

Experiments have been carried out on glare on roads and on other problems of illumination relating to transport under the Illumination Research Committee of the Department of Scientific and Industrial Research. The Bridge Stress Committee, in co-operation with the railway companies, has carried out an investigation on stresses in railway bridges, in which 52 bridges were tested and some forty different types of locomotives used, the work resulting in the withdrawal from service of certain classes of locomotives and in improved locomotive designs to reduce the unbalanced vertical forces responsible for the "hammer-blow ' and the resultant dangerous oscillations in bridges, as well as in the development of practical formulæ for bridge designers. These and similar activities assist the development of modern methods of transport on scientific lines; and the condemnation of steel tyres and the recommendation that all mechanically propelled vehicles using the roads, other than light

No. 3198, Vou. 127] 
and heavy locomotives and steam rollers, should be fitted with pneumatic tyres, are essentially based on scientific investigation and evidence.

The main difficulty, however, is that of securing action along the lines indicated by scientific and impartial examination when a large number of authorities and interests, some of which may be seriously conflicting, are involved. This is possibly illustrated by the failure of the Commission to make any real recommendation in regard to unification, the importance of which is clearly recognised. Beyond the final recommendation for the appointment of aspermanent Advisory Council on Transport, the di cussion of co-ordination leads to no unanimous conclusion. In this respect the report differs from the two earlier reports on "The Control of Traffic on Roads" and on "The Licensing and Regulation of Public Service Vehicles", the unanimous recommendations of which were practically all incorporated in the Road Traffic Bill which received Royal Assent on Aug. 1, 1930. As the report makes clear, however, the question of coordination and unification is of fundamental importance. It must ultimately be determined largely on scientific principles; and the modern traffic problem is essentially one of those problems set by seientific developments the solution and control of which rests with scientific workers themselves.

The Theory of Geological Thermal Cycles. The Surface-History of the Earth. By Dr. John Joly. Second edition. Pp. $x x i+211+13$ plates. (Oxford: Clarendon Press; London: Oxford University Press, 1930:) 8s. 6d. net.

A BOOK which has for its chief object the theses of a highly speculative character is likely soon to become out-of-date as geophysical evidence accumulates and as quantitative criticism is applied to processes envisaged in the light of incomplete knowledge. This fate rapidly befell the first edition of Prof. Joly's well-known book. It is therefore of special interest to consider how the author has dealt with recent advances bearing on his theory of thermal cycles and with the various criticisms, adverse or constructive, that represent the reactions towards it of other workers in the same field. Judged in this way, the second edition can only be regarded as disappointing.

Any discussion of the distribution of the radioactive elements in the earth must be based on the nature of the rock-types entering into the layers of the crust and of the underlying substratum.
The xenoliths brought up from the depths by the kimberlite magma of the diamond pipes of Africa suggest that the downward distribution is from granitic and gneissic rocks through amphibolite and granulite to eclogite and peridotite. Seismic evidence is consistent with such a sequence, but it fails to support Joly's new suggestion that the granite layer may be underlain by an anorthosite layer (p. 64). Moreover, the diamond pipes have provided no samples that would lend support to this assumption. Joly's view that eclogite is an important constituent of the upper part of the substratum is less hypothetical, but it is far from safe to assume that the radioactivity of such a layer is necessarily the same as that of the eclogites tested in the laboratory, since these occur for the most part in mountain belts where they owe their origin to exceptionally bigh pressure. If the plateau basalts have been derived from the complete fusion of an eclogite layer, then the radioactivity of the latter is more likely to be represented by that of therfo mer, as assumed in the first edition. By regarding the radioactivity of the substratum as thermally equivalent to about one-third that of the plateau basalts, Joly now considers the period of liquefaction to be about three times as long as his original estimate. Unfortunately, even this admission fails to make the consequences of the hypothesis consistent with the duration of geological time as estimated from lead ratios.

Much more serious, however, is the fact that Joly's mechanism of alternating accumulation and discharge of heat seems to be physically unacceptable. Jeffreys has vigorously attacked the hypothesis of thermal cycles, on the grounds that on the postulated conditions the substratum would remain permanently fluid, and that tidal drift of the crust would not occur at the required rate. But even though the proposed mechanism for bringing about the discharge of excess heat is unsatisfactory, Joly has nevertheless rendered a most important service to geology by facing the probability that there is an excess of heat to be discharged, and that some form of crustal drift is necessary to avoid the impasse of a thermally expanding globe. Possibly the underlying flaw in Joly's preliminary assumptions is his belief that because the substratum is now solid in the sense of being rigid and highly viscous, it is therefore necessarily crystalline. It may not be, at least below a certain level; quite as probably it is in a glassy state. Granting the latter assumption, which is difficult to resist from the thermal point of view, there is no difficulty in discharging heat

No. 3198, Vox. 127] 